\title{
Fetal Thymus Size in Pregnant Women with COVID-19 Infection
}

\author{
Sule GONCU AYHAN', Deniz OLUKLU' ${ }^{1}$, Selcan SINACI', Aysegul ATALAY ${ }^{1}$, Seyit Ahmet EROL ${ }^{1}$, \\ Eda OZDEN TOKALIOGLU', Muradiye YILDIRIM', Ozlem MORALOGLU TEKIN ${ }^{1,2}$, Dilek SAHIN ${ }^{1,2}$ \\ Ankara, Turkey
}

\begin{abstract}
OBJECTIVE: To determine the effect of SARS-CoV-2 infection on fetal thymus size by ultrasound.

STUDY DESIGN: In this prospective study sonographic fetal thymus size was measured in pregnant women attending our hospital with confirmed SARS-CoV-2 infection by RT-PCR test and age-matched control group. The anteroposterior thymic and the intrathoracic mediastinal diameter was determined in the three-vessel view and their quotient, the thymic-thoracic ratio, was calculated. Results were compared between these two groups.
\end{abstract}

RESULTS: Thirty-six SARS-CoV-2-infected and 47 control group pregnant women were included in this study. Two groups were similar in terms of demographic features and no difference was found for fetal thymus size.

CONCLUSION: COVID-19 seems to have no adverse effect on fetal thymus size in mild and moderate patients during the acute phase of the infection.

Keywords: COVID-19, Fetal thymus, Ultrasound

Gynecol Obstet Reprod Med 2021;27(2):84-88

\section{Introduction}

Severe acute respiratory syndrome coronavirus 2 (SARS$\mathrm{CoV}-2$ ) is a novel pathogen that causes the excessive production of proinflammatory cytokines and leading to an acute respiratory distress syndrome (1). The pathophysiology of this excessive immune response has not to been clarified yet, but the impaired response of type-1 Interferons (IFNs) in the early stage of COVID-19 infection and various cytokines such as IL-1 and IL- 6 were being accused of cytokine storm in severe

\footnotetext{
${ }^{1}$ Ministry of Health Ankara City Hospital, Department of Obstetrics and Gynecology, Ankara, TR

${ }^{2}$ University of Health Sciences, Istanbul, TR

Address of Correspondence: Sule Goncu Ayhan

Ministry of Health, Ankara City Hospital,

1604 ${ }^{\text {th }}$ Street, No: 906800 Çankaya

Ankara, Turkey

sulegoncu@gmail.com
}

Submitted for Publication: 15.05.2021 Revised for Publication: 20.05.2021 Accepted for Publication: 02.07.2021 Online Published: 02.08.2021

ORCID IDs of the authors: DO: 0000-0002-9050-2041 AA: 0000-0002-4494-9248 EOT: 0000-0003-4901-0544 SGA: 0000-0002-5770-7555 SS: 0000-0003-3118-4036 SAE: $0000-0002-2494-4896$ MY: 0000-0002-6583-2153 OMT: 0000-0001-8167-3837 DS: 0000-0001-8567-9048

\begin{tabular}{|c|c|}
\hline \multirow{3}{*}{ 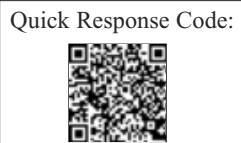 } & Access this article online \\
\hline & $\begin{array}{l}\text { Website: www.gorm.com.tr } \\
\text { e- mail: info@gorm.com.tr }\end{array}$ \\
\hline & DOI:10.21613/GORM.2021.1222 \\
\hline
\end{tabular}

How to cite this article: Goncu Ayhan S. Oluklu D. Sinaci S. Atalay A.Erol SA. Ozden Tokalioglu E. Yildirim M. Moraloglu Tekin O. Sahin D. Fetal Thymus Size in Pregnant Women with COVID-19 Infection Obstetric Outcomes. Gynecol Obstet Reprod Med. 2021;27(2):84-88
COVID-19 (2). Also, a recent study about CD4+ and CD8+ T cell responses to SARS-CoV-2 found that all recovered patients established CD4+ responses, and 70\% established CD8+ memory responses to SARS-CoV-2 and strong SARSCoV2-specific $\mathrm{T}$ cell responses were observed in patients who had severe disease (3).

Pregnancy seems to worsen the clinical outcomes of coronavirus disease 2019 (COVID-19) compared with same-age non-pregnant women $(4,5)$. Additionally, after a year with this disease, we know that obstetric complications such as preterm labor, fetal distress, and stillbirths increase $(5,6)$. Excessive inflammation, altered immune response, and decreased maternal oxygen saturation might be the reasons for these complications. In addition, placental findings like decidual arteriopathy, villitis, and intervillous thrombi might increase these obstetric adverse outcomes (7).

The thymus is one of the main lymphatic organs responsible to produce $\mathrm{T}$ lymphocytes and the development of the fetal immune system. Its development starts in the fifth gestational week from the endoderm. Then, lymphatic progenitor cells from other immune organs like the liver and spleen start to immigrate around the ninth week of gestation which will form thymocytes (8). The maturation and differentiation of thymocytes to $\mathrm{T}$ lymphocytes also occurs in the thymus gland and this change is essential for a healthy immune system. Around 16-20 weeks of gestation fetal thymus development completed (9). Decreased fetal thymus size was demonstrated after fetal immune response syndrome (FIRS), due to chorioamnionitis with preterm premature rupture of membranes 
(PPROM) (10). Also, reduced size of this organ was shown in pregnancies complicated with preeclampsia, intrauterine growth restriction (IUGR), diabetes mellitus (DM), and fetuses with chromosomal abnormalities $(11,14)$.

Regretfully, the fetal effects of SARS-CoV-2 infection are still uncertain. In our previous study, we found that COVID19 infection has no negative effect on Doppler parameters in pregnant women (15). However, due to hyper inflammation, hypoxia, and stress-related conditions; fetal thymus size might be reduced in COVID-19 positive pregnancies.

In the present study, we aimed to determine fetal thymus sizes in COVID-19-infected pregnant women to investigate the effect of infection on the fetal immune system.

\section{Material and Method}

This is a prospective study that was conducted between August 1, 2020, and October 1, 2020, in the Turkish Ministry of Health Ankara City Hospital with pregnant women confirmed to SARS-CoV-2 infection. Positive RT-PCR results were used for infection confirmation. Patients who tested positive were hospitalized for mild or moderate COVID-19 were compared with an age-matched control group of pregnant women monitored for routine antenatal care. There were no severe or critical cases COVID-19 positive group. Maternal systemic diseases, multifetal pregnancies, growth-restricted fetuses, and fetal structural heart anomalies were used as exclusion criteria. Also, pregnant women with any symptoms of COVID-19 infection (fever, cough, myalgia, etc.) were not included in the control group. Written informed consent was obtained from all participants. The study was conducted by the Declaration of Helsinki. The applied protocol was approved by the Turkish Ministry of Health and Medical Research Ethics Department of the hospital (E1-20-1169) on October 28, 2020.

The gestational age of the patients determined by the last menstrual period or first-trimester crown-rump length. Thymus measurements were performed between 28 and 36 weeks of gestation. Same maternal-fetal medicine specialists performed ultrasound (USG) evaluation with the software of the GE Voluson S10 Ultrasound machine C1-5-RS convex probe (1.75-4.95 Mhz). Personal protective equipment was used by researchers during USG exams of patients infected with COVID-19. To avoid orthostatic hypotension, examinations were performed in a semi-Fowler position. The thymus was identified in the anterior mediastinum, in front of the great vessels, at the level of the three-vessel view as a homogeneous structure. A transversal section of the fetal thorax in the threevessel view was used for the measurement of the fetal thymus size. The fetal sternum and the fetal spine were defined for proper measurement. Thymus diameter (anteroposterior thymus diameter) was measured from the posterior edge of the fetal sternum through the aorta and thorax diameter (intrathoracic mediastinal diameter) was measured from the posterior edge of the fetal sternum through the anterior edge of the fetal vertebra (Figure 1). The Thymic-thoracic ratio (TTR) was calculated as follows: thymus diameter/thorax diameter.

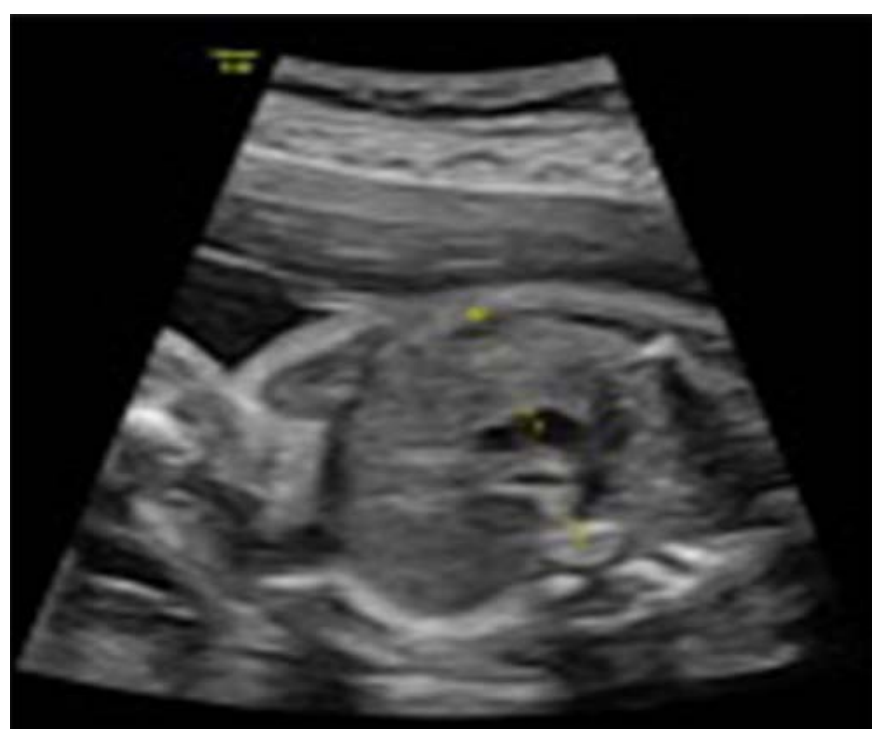

Figure 1: A transversal section of the fetal thorax in the threevessel view. Thymus diameter (anteroposterior thymus diameter): from the posterior edge of the fetal sternum through the aorta. Thorax diameter (intrathoracic mediastinal diameter): from the posterior edge of the fetal sternum through the anterior edge of the fetal vertebra

Sonographic measurements were performed before betamethasone administration. Clinical characteristics were collected prospectively by researchers.

SPSS 17 was used for statistical analysis. The ShapiroWilk test, Kolmogorov-Smirnov test were used to determine the normality distribution of the data. The continuous variables were presented as mean and standard deviations. Groups were compared with The independent-sample t-test. A type-1 error below 0.05 was considered statistically significant.

\section{Results}

Table I shows the demographic features of patients with COVID-19 $(n=36)$ and patients in the control group $(n=47)$. The two groups were homogenous, and no significant differences were noted in the demographic data. When the TTR were compared, no difference was found between the COVID-19 group and the controls. Table II provides a comparison of the TTR parameter.

\section{Table I: Demographic data}

\begin{tabular}{lrcc}
\hline Variables & $\begin{array}{c}\text { COVID-19 } \\
+ \text { group } \\
(\mathrm{n}=36)\end{array}$ & $\begin{array}{c}\text { Control } \\
\text { group } \\
(\mathrm{n}=47)\end{array}$ & $\mathrm{p}$ \\
\hline Age (years) (mean $\pm \mathrm{SD})$ & $28.7 \pm 5.3$ & $27 \pm 5.5$ & 0.432 \\
Gravidity (mean $\pm S D)$ & $1.86 \pm 1.1$ & $1.74 \pm 1.2$ & 0.341 \\
Parity (mean $\pm S D)$ & $0.88 \pm 0.6$ & $0.71 \pm 0.6$ & 0.412 \\
Gestational Week (mean $\pm S D)$ & $34 \pm 3.7$ & $34.3 \pm 3.2$ & 0.076 \\
\hline
\end{tabular}


Table II: Fetal Ultrasound Parameters

\begin{tabular}{lccc}
\hline Variables & $\begin{array}{c}\text { COVID-19+group } \\
(\mathrm{n}=36)\end{array}$ & $\begin{array}{c}\text { Control group } \\
(\mathrm{n}=47)\end{array}$ & $p$ \\
\hline TTR (mean $\pm S D)$ & $0.34 \pm 0.78$ & $0.35 \pm 0.78$ & $0.469^{*}$ \\
\hline
\end{tabular}

TTR: Thymic-Thoracic Ratio, * Independent T-test

\section{Discussion}

COVID-19 is a multisystem infectious disease that is wellknown to cause hyper inflammation and cytokine storm as an immune response $(16,17)$. The fetal thymus plays a leading role against infection and inflammation and effected negatively in the presence of maternal infections $(10,18)$. Due to hyper inflammation, hypoxia, and stress-related conditions; we thought fetal thymus size might be reduced in COVID-19 positive pregnancies. Surprisingly, the present study did not find any difference in fetal TTR parameters between COVID19 positive pregnant women and controls.

In our study, TTR was used to evaluate thymus size because it is not influenced by body mass index or fetal gender $(13,19)$. Therewithal, it is constant throughout gestation and the mean TTR was 0.44 in normal fetuses, independent of gestational age when the ratio was significantly smaller, being below 0.3 and with a mean of 0.25 in fetuses with congenital heart diseases and microdeletion $22 q 11$ (20). We found a mean TTR of $0.34 \pm 0.78$ in the COVID-19 group and $0.35 \pm 0.78$ in the control group which was in a normal range.

The fetal immunologic effect of maternal infections has been searched several times before. De Felice et al. showed that the thymus size was markedly decreased in subclinical chorioamnionitis in PPROM patients (10). Yinon et al. reported decreased fetal thymus size with PPROM and chorioamnionitis and found an interesting result that small thymus has a positive predictive value of $69 \%$ for chorioamnionitis and raise the possibility of infection (21). This involution is associated with corticomedullary decrease and lymphocyte migration towards affected organs and apoptotic process of thymocytes which is a result of hypothalamic-pituitary-adrenal axis activation by the acute response to infection $(22,23)$. FIRS is a subclinical condition and includes fetal immune system activation that results in the rise of proinflammatory cytokines (24). This situation might be against both microorganisms and non-microbial fragments. High concentrations of various cytokines like IL-1, IL-6, TNF- $\alpha$ demonstrated in cord blood of fetuses with intra-amniotic infection or inflammation before (18). Small thymus size pointed as a sonographic marker of FIRS in several studies $(25,26)$. A recent case report has indicated that fetal inflammatory response syndrome is caused by SARS-CoV-2 (27). Therefore, we thought fetal thymus size might be affected negatively by COVID-19 infection-related events, such as increased cytokine levels and acute respiratory distress. However, we could not find any difference in TTR between COVID-19 positive and control groups. Our COVID-19 infected pregnant women were in the acute phase of infection and had a mild or moderate category of the illness. This might be the explanation of the present study results.

Gasthaus et al. published research about the thymus size of the human immunodeficiency virus (HIV) exposed fetuses (8). They found that HIV-exposed fetuses have increased thymus size. Writers explained this situation with altered placental production of inflammatory cytokines in HIV-positive mothers. Also, continuous exposure to HIV antigens throughout gestation might cause stimulation of T-cells activation and increase to the thymic cortex. COVID-19 is an acute infection and patients recover mostly for two weeks. Additionally, vertical transmission to the fetus has not been demonstrated to date $(28,29)$, explaining the findings of the lack of negative effects of the virus on the fetal immune system.

Relation with fetal thymus size and maternal diseases also exists in the literature. Mohamed et al. reported an association between pre-eclampsia with a small fetal thymus (12). There is another study showed reduced fetal thymus size in diabetic pregnancies compared with controls (13). Medical stresses during pregnancy cause activation of the hypotalamo-pituitary-adrenal axis and cortisol release in the fetus and triggered fetal thymus involution (30). Also, these medical conditions occur for a long-time period before they become obvious. We did not find any difference in the acute phase of the COVID-19 infection but we think long-time outcomes can be different.

COVID-19 is still an undiscovered field after more than a year. Even though SARS-CoV-2 virions were identified in the placental villi microscopically (31), vertical transmission is not yet be proven $(28,29)$. The viruses' fetal effects are still keeping their mystery and this issue must be clarified with further studies focused on both acute and long-time fetal outcomes.

The main strengths of our study were its novelty and prospective design. The main limitations were the relatively low number of COVID-19 cases, no severe category participants in the COVID-19 group, and a lack of information related to the long-term outcomes of the fetuses.

In conclusion, COVID-19 infection seems to have no effect on fetal thymus size in pregnant women with mild/moderate symptoms in the acute phase of the infection. Best of our knowledge this is the first study evaluating this effect of SARS-CoV-2 in literature. Further studies of larger numbers of patients are necessary to confirm the result reported here.

Acknowledgment: The authors give special thanks to all the healthcare staff at the hospital, who work so hard during the pandemic period. 
Conflict of interest statement: All authors state that they have no conflict of interest in this study.

Funding: None

Ethics: The applied protocol was approved by the Turkish Ministry of Health and Medical Research Ethics Department of the hospital (E1-20-1169) on October 28, 2020.

Availability of data and materials: The data supporting this study is available through the corresponding author upon reasonable request. The datasets and code used and/or analyzed during the current study are available from the corresponding author on reasonable request

Authors' contributions: SGA raised the presented idea. SGA and DS designed the study. SGA developed the first draft of the manuscript. SGA conducted the population study, analyzed and interpreted the data, and drafted the manuscript. SS, AA, $D O$, assisted with data collection and analysis. OMT participated in interpretation, and draft revision. DS critically revised the manuscript. All authors contributed to the writing of the paper, and have read and approved the final manuscript. All authors read and approved the final manuscript.

\section{References}

1. Tufan A, Avanoğlu Güler A, Matucci-Cerinic M. COVID-19, immune system response, hyperinflammation and repurposing antirheumatic drugs. Turk J Med Sci. 2020;50(SI-1):620-32. Doi:10.3906/sag-2004-168.

2. Kim JS, Lee JY, Yang JW, Lee KH, Effenberger M, Szpirt $\mathrm{W}$, et al. Immunopathogenesis and treatment of cytokine storm in COVID-19. Theranostics. 2021;11(1):316-29. Doi: $10.7150 /$ thno.49713.

3. Grifoni A, Weiskopf D, Ramirez SI, Mateus J, Dan JM, Moderbacher CR, et al. Targets of $\mathrm{T}$ cell responses to SARS-CoV-2 Coronavirus in humans with COVID-19 disease and unexposed individuals. Cell. 2020;181(7): 1489-1501.e15. Doi: 10.1016/j.cell.2020.05.015.

4. Zambrano LD, Ellington S, Strid P, Galang RR, Oduyebo T, Tong VT, et al. Update: Characteristics of Symptomatic Women of Reproductive Age with Laboratory-Confirmed SARS-CoV-2 Infection by Pregnancy Status-United States, January 22-October 3, 2020. MMWR Morb Mortal Wkly Rep. 2020;69(44):1641-7. Doi: 10.15585/mmwr. mm6944e3.

5. Turan O, Hakim A, Dashraath P, Jeslyn WJL, Wright A, Abdul-Kadir R. Clinical characteristics, prognostic factors, and maternal and neonatal outcomes of SARS-CoV2 infection among hospitalized pregnant women: A systematic review. Int J Gynaecol Obstet. 2020;151(1):7-16. Doi: 10.1002/ijgo.13329.

6. Sahin D, Tanacan A, Erol SA, Anuk AT, Yetiskin FDY, Keskin HL, et al. Updated experience of a tertiary pandemic center on 533 pregnant women with COVID-19 infection: A prospective cohort study from Turkey. Int J Gynaecol Obstet. 2021;152(3):328-34. Doi: 10.1002/ijgo. 13460
7. Shanes ED, Mithal LB, Otero S, Azad HA, Miller ES, Goldstein JA. Placental pathology in COVID-19. Am J Clin Pathol. 2020;154(1):23-32. Doi: 10.1093/ajcp/aqaa 089.

8. Gasthaus CL, Schmitz R, Hammer K, Oelmeier de Murcia $\mathrm{K}$, Falkenberg MK, Braun J, et al. Influence of maternal HIV infection on fetal thymus size. J Perinat Med. 2019;48(1):67-73. Doi: 10.1515/jpm-2019-0060

9. Gordon J, Manley NR. Mechanisms of thymus organogenesis and morphogenesis. Development. 2011;138(18): 3865-78. Doi: 10.1242/dev.059998.

10. De Felice C, Toti P, Santopietro R, Stumpo M, Pecciarini L, Bagnoli F. Small thymus in very low birth weight infants born to mothers with subclinical chorioamnionitis. J Pediatr. 1999;135(3):384-6. Doi: 10.1016/s0022-3476(99) 70140-x.

11. Cromi A, Ghezzi F, Raffaelli R, Bergamini V, Siesto G, Bolis P. Ultrasonographic measurement of thymus size in IUGR fetuses: a marker of the fetal immunoendocrine response to malnutrition. Ultrasound Obstet Gynecol. 2009;33(4):421-6. Doi: 10.1002/uog.6320.

12. Mohamed N, Eviston DP, Quinton AE, Benzie RJ, Kirby AC, Peek MJ, et al. Smaller fetal thymuses in pre-eclampsia: a prospective cross-sectional study. Ultrasound Obstet Gynecol. 2011;37(4):410-5. Doi: 10.1002/uog.8953.

13. Dörnemann R, Koch R, Möllmann U, Falkenberg MK, Möllers M, Klockenbusch W, et al. Fetal thymus size in pregnant women with diabetic diseases. J Perinat Med. 2017;45(5):595-601. Doi: 10.1515/jpm-2016-0400.

14. Karl K, Heling KS, Sarut Lopez A, Thiel G, Chaoui R. Thymic-thoracic ratio in fetuses with trisomy 21,18 or 13. Ultrasound Obstet Gynecol. 2012;40(4):412-7. Doi: 10.1002/uog.11068.

15. Ayhan SG, Tanacan A, Atalay A, Sinaci S, Tokalioglu EO, Sahin D et. al. Assessment of fetal Doppler parameters in pregnant women with COVID-19 infection: a prospective case-control study. J Perinat Med. 2021. Doi: 10.1515/jpm-2020-0512.

16. Hu B, Huang S, Yin L. The cytokine storm and COVID19. J Med Virol. 2021;93(1):250-6. Doi: 10.1002/jmv. 26232

17. Tanacan A, Yazihan N, Erol SA, Anuk AT, Yucel Yetiskin FD, Biriken D, et al. The impact of COVID-19 infection on the cytokine profile of pregnant women: A prospective case-control study. Cytokine. 2021;140: 155431. Doi: 10.1016/j.cyto.2021.155431.

18. Sciaky-Tamir Y, Hershkovitz R, Mazor M, Shelef I, Erez $\mathrm{O}$. The use of imaging technology in the assessment of the fetal inflammatory response syndrome-imaging of the fetal thymus. Prenat Diagn. 2015;35(5):413-9. Doi: 10.1002/pd.4560.

19. De Leon-Luis J, Gámez F, Pintado P, Antolin E, Pérez R, Ortiz-Quintana L, et al. Sonographic measurements of the 
thymus in male and female fetuses. J Ultrasound Med. 2009;28(1):43-8. Doi: 10.7863/jum.2009.28.1.43.

20. Chaoui R, Heling KS, Lopez AS, Thiel G, Karl K. The thymic-thoracic ratio in fetal heart defects: a simple way to identify fetuses at high risk for microdeletion $22 \mathrm{q} 11$. Ultrasound Obstet Gynecol. 2011;37(4):397-403. Doi: 10.1002/uog.8952.

21. Yinon Y, Zalel Y, Weisz B, Mazaki-Tovi S, Sivan E, Schiff E, et al. Fetal thymus size as a predictor of chorioamnionitis in women with preterm premature rupture of membranes. Ultrasound Obstet Gynecol. 2007;29(6):639-43. Doi: 10.1002/uog.4022.

22. Kuypers E, Wolfs TG, Collins JJ, Jellema RK, Newnham JP, Kemp MW, et al. Intraamniotic lipopolysaccharide exposure changes cell populations and structure of the ovine fetal thymus. Reprod Sci. 2013;20(8):946-56. Doi: $10.1177 / 1933719112472742$.

23. De Felice C, Toti P, Musarò M, Peruzzi L, Paffetti P, Pasqui L, et al. Early activation of the hypothalamic-pituitary-adrenal-axis in very-low-birth-weight infants with small thymus at birth. J Matern Fetal Neonatal Med. 2008;21(4):251-4. Doi: 10.1080/14767050801927871.

24. Gomez R, Romero R, Ghezzi F, Yoon BH, Mazor M, Berry SM. The fetal inflammatory response syndrome. Am J Obstet Gynecol. 1998;179:194-202. Doi: 10.1016/ s0002-9378(98)70272-8.

25. El-Haieg DO, Zidan AA, El-Nemr MM. The relationship between sonographic fetal thymus size and the components of the systemic fetal inflammatory response syndrome in women with preterm prelabour rupture of membranes. BJOG. 2008;115(7):836-41. Doi: 10.1111/j.1471- 0528.2008.01715.x.

26. Mastrolia SA, Erez O, Loverro G, Di Naro E, Weintraub AY, Tirosh D, et al. Ultrasonographic approach to diagnosis of fetal inflammatory response syndrome: a tool for at-risk fetuses? Am J Obstet Gynecol. 2016;215(1):9-20. Doi: 10.1016/j.ajog.2016.01.164.

27. McCarty KL, Tucker M, Lee G, Pandey V. Fetal inflammatory response syndrome associated with maternal SARS-CoV-2 infection. Pediatrics. 2020:e2020010132. Doi: 10.1542/peds.2020-010132.

28. Yang Z, Liu Y. Vertical transmission of Severe Acute Respiratory Syndrome Coronavirus 2: A systematic review. Am J Perinatol. 2020;37(10):1055-60. Doi: 10.1055/s-0040-1712161.

29. Karimi-Zarchi M, Neamatzadeh H, Dastgheib SA, Abbasi $\mathrm{H}$, Mirjalili SR, Behforouz A, et al. Vertical transmission of Coronavirus Disease 19 (COVID-19) from infected pregnant mothers to neonates: A review. Fetal Pediatr Pathol. 2020;39(3):246-50. Doi: 10.1080/15513815. 2020.1747120

30. Gravett MG, Hitti J, Hess DL, Eschenbach DA. Intrauterine infection and preterm delivery: evidence for activation of the fetal hypothalamic-pituitary-adrenal axis Am J Obstet Gynecol. 2000;182(6):1404-13. Doi: 10.1067/mob.2000.106180.

31. Algarroba GN, Rekawek P, Vahanian SA, Khullar P, Palaia T, Peltier MR, et al. Visualization of severe acute respiratory syndrome coronavirus 2 invading the human placenta using electron microscopy. Am J Obstet Gynecol. 2020;223(2):275-8. Doi: 10. 1016/j.ajog. 2020. 05.023 . 